\title{
The categorization of perceived threat: Prototypicality of in-group and out-group
}

Tolga Ergiyen, Günce Yavuz

İstanbul Kültür University, İzmir University of Economics

\section{Abstract}

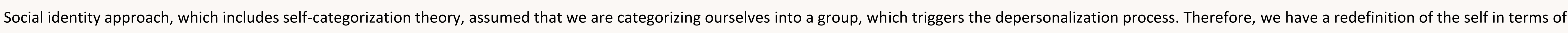

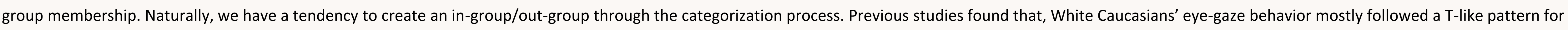

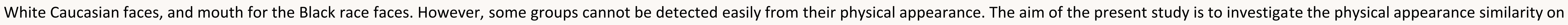

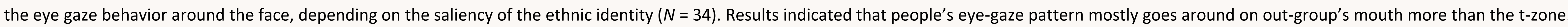

Our perception is affect introduction

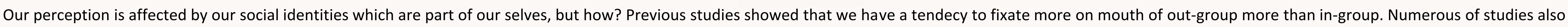

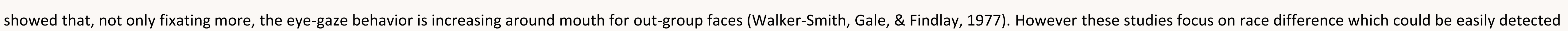
by physical appearance. This study focus on eye gaze behavior towards different ethnicities.

\begin{abstract}
Method
Participants

Thirty-eight university student took part (Mage $=22.07$, $S D=1.25$ ). All participants have normal vision. Participants who were using contact lenses or eyeglasses and who were wearing eye makeup excluded from the study. Materials

SMI Experiment Center version 3.4 (SensoMotoric Instruments, $\mathrm{GmhbH}$.) was used to present faces to participants via a desktop computer on a 22-inch monitor. The iView $\mathrm{X}$ system used for data recording. A chin rest used to fixate the eye distance of the
\end{abstract} participants (60-65 $\mathrm{cm}$ distance from the monitor). SMI Experiment Center AOI (Area of Interest) Editor specified the Tzone (eyes and nose) and mouth areas.

Procedure

First, participants were informed about the experiment, filled Inform Consent and Demographic Form. Second, they filled the Perceived Threat Scale. For the Eye-Tracker recordings, participants saw two different sets of faces (Syrian and Turkish) with two different labeling (Syrian and Turkish). Twentyfour face pictures were shown under four different conditions. Perceived similarity/difference of all faces are determined with a pilot study $(N=114)$. It was expected from the participants to scan the faces during the 7 seconds period.

Corresponding author: t.ergiyen@iku.edu.tr
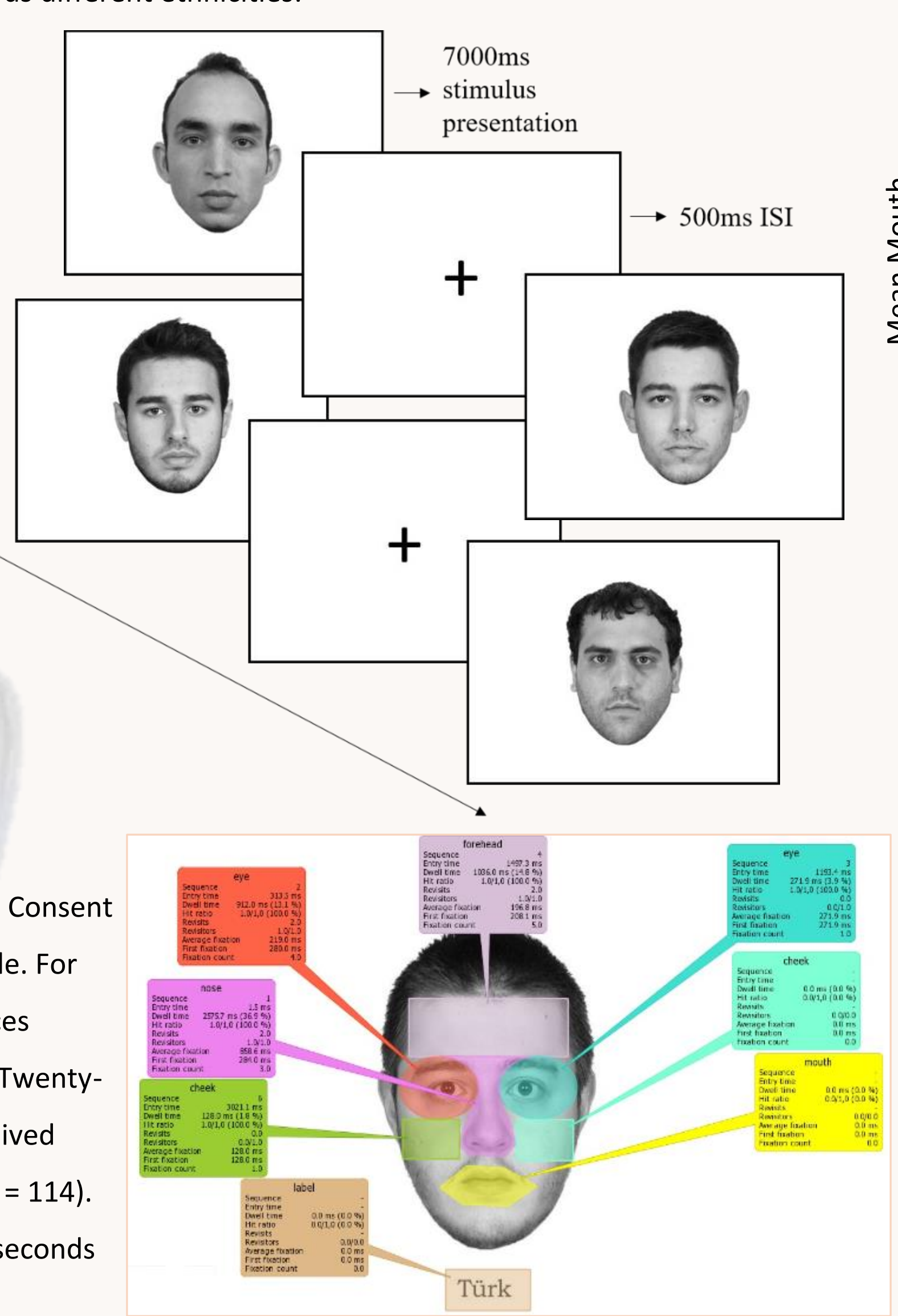

*Special thanks to our dear student Ezgi Yaldız from Izmir Univeristy of Economics

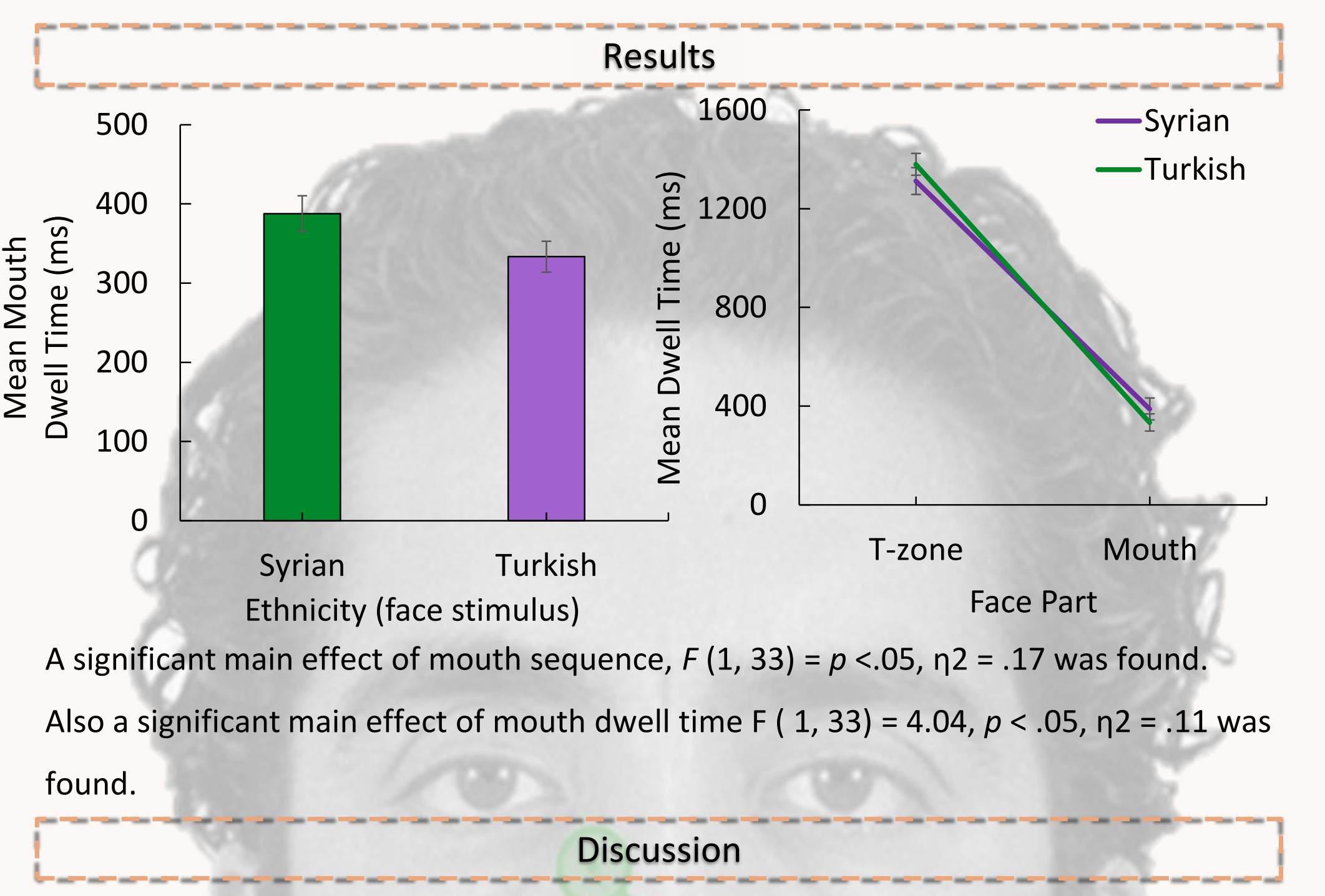

Our results indicated that, people's eye-gaze pattern mostly goes around on outgroup's mouth more than the t-zone. Previous studies showed, the eye gaze pattern of the one race differentiates while looking at other race face; more eye-gaze patterns of the white people on mouth, rather than the t-zone for black race face. This study creates a new perspective by applying the results in the liretature, and showed the same gaze pattern for people from different ethicities which cannot be easly detected from physical appereance.

\section{References}

Walker-Smith, G. J., Gale, A. G., \& Findlay, J. M. (1977). Eye movement strategies involved in face perception. Perception, 6(3), 313-326. 